\title{
Sinteza
}

Impact of Internet on Business Activities

in Serbia and Worldwide

Uticaj Interneta na poslovanje u Srbiji i

svetu

DOI: $10.15308 /$ SINTEZA-2014-217-220

\section{LJUDSKI RESURSI I PREDUZETNIČKA KULTURA U SAVREMENIM KORPORACIJAMA}

\author{
Svetislav Paunović \\ BBA Fakultet za bankarstvo, osiguranje i finansije, Beograd
}

\begin{abstract}
:
Korporacije su danas, kao nikada do sada, pod velikim pritiskom konstantnog dokazivanja i potvrđivanja svoje konkurentske pozicije na tržištu. Nema trajnih konkurentskih prednosti, ono što je juče urađeno danas treba unaprediti i inovirati kako bi se opstalo u turbulentnom okruženju. Nije dovoljno samo osluškivati potrebe tržišta i prilagođavati se njima, već je potrebno definisati strategiju poslovanja koja je bazirana na spoznaji novih mogućnosti i kreiranju novih potreba tržišta kroz razvoj različitih oblika inovacija. Reaktivni pristup sve vise ustupa mesto proaktivnom koji znači punu implementaciju korporativnog preduzetništva. Od izuzetne važnosti je pitanje izgradnje adekvatnog modela korporativne kulture koji inkorporira elemente preduzetništva. U radu su elaborirane osnovne vrednosti preduzetničke kulture kao i motivacioni faktori koji pomažu da se vrednosti ove kulture implementiraju u korporativnom okruženju. Razvoj savremenih informaciono-komunikacionih tehnologija omogućava kreiranje fleksibilnijih formi organizacije sa organizacionom kulturom koja podstiče inovativnost i razvoj ljudskih resursa ali sve više i uzajamno poverenje i zajedničku posvećenost.
\end{abstract}

\section{Key words:}

Korporativno preduzetništvo, korporativna kultura, preduzetnička kultura.

\section{EKSTERNO OKRUŽENJE I POSLOVNI IZAZOVI}

Eksterno poslovno okruženje globalno posmatrano karakterišu sve kompleksnije promene koje su veoma dinamične po svom intenzitetu. Te promene nisu vise inkrimentalnog karaktera, one postaju konstantne i radikalne inovacije posebno u granama informaciono-komunikacionih tehnologija. Pored toga, konkurencija jača, što u prvi plan postavlja sve veće zahteve savremenim korporacijama po pitanju kvaliteta proizvoda. Kvalitet baziran na inovacijama postaje imperativ i uslov bez koga nema napretka i očuvanja tržišne pozicije. Ono što je juče urađeno i što je donelo uspeh, danas nije dovoljno, što postavlja nove i više standarde. Da bi se opstalo u turbulentnom okruženju potrebno je konstantno raditi na inovacijama pri čemu nepredvidivo okruženje sve vise diktira potrebu definisanja takvih strategija koje će u prvi plan staviti ne samo prilagođavanje potrebama kupaca već i kreiranje njihovih novih potreba.

Korporacije su danas vise nego ikada pod velikim pritiskom da svoje organizacione sisteme učene efikasnijim i konkurentnijim kako bi održali i unapredili svoju tržišnu poziciju. Ne postoje trajne konkurentske prednosti. Organizacija može da bude bolja od konkurencije samo ako svoje konkurentske prednosti održava u jednom dužem vremenskom period. Korporacije sve više postaju organizacije koje uče. Međutim, za opstanak u tržišnoj areni nije dovoljno samo učiti, već ućiti brže od konkurencije.
Organizacija se prilagođava promenama ali i kreira pormene samo ako je sposobna da uči brže i više. Znanje na početku 21. veka postaje osnovni faktor održivog razvoja. Nisu više u prednosti organizacije koje imaju pristup prirodnim resursima, tehnologiji ili finansijskim resursima, već one koje imaju izgrađen sistem kontinuiranog učenja i sticanja znanja sa ciljem kreiranja najboljeg proizvoda ili usluge na tržištu. Jezgro kompetentnosti organizacije se izgrađuje samo kroz procese učenja. Konkurentsku prednost poznate korporacije sve više zasnivaju na neopipliivoj impovini (intangible assets) i procena je da ona u iznosi preko $80 \%$ njihove ukupne imovine. U vremenu turbuletnih promena ovakva akumulirana znanja zastarevaju izuzetno brzo. Znanja iz oblasti tehnoloških nauka stečena pre dvadesetak godina, pod predpostavkom da nisu inovirana, danas vrede svega nekih $10 \%$. Organizacija koja uči ima sposobnost da relatvino brzo i lako unapređuje procedure i rutine u obavljanju poslovnih aktivnosti gradeći na taj način nove kompetencije.

\section{INTERNO OKRUŽENJE I KORPORATIVNO PREDUZETNIŠTVO}

U borbi za unapređenje poslovnih rezultata organizacije se susreću sa nekoliko pitanja. Najčešće su to rastuća konkurencija na tržištu, erozija liderstva i preduzetničkog stila upravljanja, osećaj samozadovoljstva tj. samouverenosti koji ometa organizacione promene i nezadovoljavajući kvalitet 
i nedovoljna osposobljenost menadžment ekipe da izgradi organizacionu infrastrukturu koja može da udovolji i podrži zahteve organizacionog rasta.

Možda deluje kontradiktorno, ali problemi sa kojima se organizacije suočavaju su rezultat samog uspeha organizacije. Sa uspehom dolazi rast organizacije, a on kreira određeni stepen otpora promenama, u eksternom okruženju ali i u internom sistemu. Osnovni problem koji procese promena i revitalizacije čini teškim leži u činjenici da organizacija u ovoj fazi razvoja mora da se skoncentriše simultano na nekoliko ključnih organizacionih razvojnih ciljeva [1]:

- redefinisanje tržišta

- redefinisanje proizvoda tj. usluge

- redefinisanje resursa

- redefinisanje operativnih sistema

- revitalizaciju menadžment sistema

- kreiranje modela korporativne kulture sa posebnim akcentom na jačanje elemenata preduzetničke kulture.

Imajući u vidu da je organizacija možda uključena na veći broj zrelih tržišta, na kojima su stope rasta i stope profita u padu, zbog pada prihoda i rasta operativnih troškova koji su prouzrokovani rastućom veličinom firme i njenom nedovoljnom efikasnošću, postavlja se pitanje redefinisanja tržišta, ali i redefinisanja proizvoda (usluge). Preispitivanje i prekomponovanje resursa kao i redefinisanje menadžment sistema se neminovno nameću kao bitna pitanja. Sistem planiranja čak i da je dobro razvijen možda nije dovoljno preduzetnički orijentisan, organizaciona struktura mora u određenoj meri da ostvari veći stepen autonomije, potrebno je kreirati timove menadžera koji razmišljaju više kao preduzetnici a manje kao profesionalni menadžeri, pri čemu preduzetništvo i preduzetničko ponašanje postaju jedna od krucijalnih dimenzija procesa revitalizacije. I možda najvažnije, model organizacione kulture u nedovoljnoj meri podržava korporativno preduzetništvo pri čemu sistem vrednosti organizacione kulture kao i motivacioni faktori nisu dovoljno dobro uklopljeni $\mathrm{u}$ organizacioni model.

Poneseni inercijom uspešnog poslovanja utabanim stazama u relativno dužem vremenskom periodu, organizacije ulaze u svojevrsne veoma specifične probleme ukoliko se ne rukovode strategijom prevazilaženja onoga što je juče uspešno urađeno. Drugim rečima, suočeni sa činjenicom da inicijalnim zamajcem rasta i razvoja nije moguće održati biznis na putanji uspona, vlanisci u prvi plan ističu potrebu razvijanja preduzetničkog duha i inovativne klime na svim organizacionim nivoima, od vrha menadžment strukture do svakog operativnog radnika.

Ponekada je veoma teško ponoviti briljantan inicijalni preduzetnički uspeh iz prošlosti i u tom kontekstu možda nije realno očekivati da neko ko je svojom vizijom nekada kreirao biznis, treba da radi na njegovom konstantnom razvoju i u budućnosti i da pri tome preuzme isključivu odgovornost za njegove poslovne rezultate. Potrebna je timska podrška preduzetnički orijentisanih saradnika. Čak i najbriljantniji primeri korporativnog preduzetništva danas ukazuju da je bez kvalitetnog tima skoro nemoguće konstantno potvrđivanje i dokazivanje na tržištu kao i ostvarivanje održive konkurentske pozicije. U današnjem turbulentnom okruženju, organizacije pronalaze svoj modus vivendi $u$ paralelnom profitiranju na dva fronta: $u$ korišćenju pozitivnih efekata ekonomije obima i u implementaciji korporativnog preduzetništva.

Preduzetnički duh je jedan od ključnih faktora uspeha. Sve su manje cenjeni oni zaposleni koji čekaju naređenje ili instrukciju pretpostavljenog, kao i oni koji su naučili na rutinsko izvršavanje zadataka po principu ,zašto nešto menjati kada je to do sada dobro funkcionisalo i donosilo dobre rezultate". Sve su traženiji, potrebniji i bolje plaćeni oni koji pokazuju kreativnost i inicijativu u realizaciji novih poslovnih poduhvata kroz kreiranje novog biznisa unutar ili izvan postojeće organizacije.

Da bi išla u susret rešavanju problema, organizacija mora iz korena da se inovira, ona mora iznova da postane preduzetnička. Ono što je potrebno jeste jačanje preduzetništva u organizaciji, ali na bitno drugačijim osnovama. Umesto da su pogledi uprti u jednog čoveka - preduzetnika, organizacija mora da kreira timove preduzetnika. Pri tome, potrebni su ljudi koji će biti posvećeni određenom biznisu kao da su u svom sopstvenom biznisu i pri tome tretirani više kao partneri u biznisu.

Poslovne performanse kritično zavise od sposobnosti organizacije da kreira adekvatan model koji će podsticati preduzetničko ponašanje i uspostavljanje odgovarajućih kanala komunikacije koji motivišu zasposlene da ispoljavaju kreativnost i inovativnost u svakom terenutku i na svakom mestu radeći konstantno na sopstvenom razvoju. Drugim rečima, potrebno je korporativno preduzetništvo i odgovarajuća organizaciona kultura koja podržava preduzetništvo.

\section{ORGANIZACIONA KULTURA KOJA PODRŽAVA PREDUZETNIŠTVO}

Organizaciona kultura kao soft komponenta organizacionog razvoja podrazumeva sistem vrednosti i normi ponašanja kao i skup odgovarajućih motivacionih faktora koji podstiču njenu efikasnu implementaciju. Organizacionu kulturu treba uvek posmatrati u strateškom kontekstu i kao veoma bitnu polugu u procesu donošenja menadžment odluka. Pretpostavka je da su organizacije uspešne upravo zato što imaju kulturu koja u prvi plan ističe potrebu stalnog prilagođavanja promenama, za razliku od onih kod kojih organizaciona kultura utiče negativno na sposobnost prilagođavanja. Ona takođe može da bude veoma moćan instrument koji olakšava i ubrzava procese koordinacije. Zaposleni, polazeći od istih pretpostavki i vrednosti, se lakše razumeju i efikasnije koordiniraju svoje aktivnosti, a organizaciona kultura u značajnoj meri zamenjuje formalne mehanizme koordinacije kao što su pisane procedure. Organizaciona kultura je i efikasan mehanizam kontole ponašanja zaposlenih. Prihvatanjem određenih vrednosti i normi od strane zaposlenih bitno se pojednostavljuje kontrola njihovog ponašanja, pri čemu kontrola pojedinaca dolazi iznutra. Organizaciona kultura može bitno da relativizuje i smanji konflikte u organizaciji i doprinese da stavovi zaposlenih, koji su često veoma različiti, mogu lakše da se usaglašavaju i na 
taj način predstavljaju manji problem prilikom donošenja odluka. Snažna kultura je i dobar motivator jer doprinosi poistovećivanju zaposlenih sa organizacijom i stvaranju osećaja pripadanja organizaciji [2].

Kreiranje pozitivne organizacione kulture [3] podrazumeva kreiranje ambijenta u kome je akcenat na:

- mogućnostima i snazi (komparativnim prednostima) zaposlenih

- nagrađivanju a manje na kažnjavanju

- ukupnom razvoju zaposlenih, a ne samo na organizacionoj efektivnosti.

U okvirima ovog koncepta treba tražiti ključne vrednosti preduzetničke kultura [4]:

- Preduzetnička kultura podrazumeva pozitivan stav i otvorenost za promene bez obzira odakle one dolazile. Najuspešnije organizacije izgrađuju kulturu koja pozdravlja promene i šanse koje one donose [5]. Promene nisu pretnja za organizaciju već mogućnost i šansa. Orijentacija na promene vremenom postaje deo kulture organizacije. Uslovi na tržištu zahtevaju da se organizacije ne samo prilagođavaju promenama u okruženju već i da rade na njihovom kreiranju, pri čemu je stvaranje najbolje vrednosti za potrošače vrhovni cilj. Umesto da su reaktivne, organizacije sve više moraju da budu proaktivne.

- Johnson \& Johnson i Intel su kompanije poznate po permanentnim proizvodnim inovacijama [6], saradnici kompanije 3M imaju 15\% slobodnog vremena za razmišljanje, SATURN je poznat po tzv. krugovima kvaliteta, a TOYOTA po veoma razvijenom sistemu sugestija. Ove organizacije u svojoj korporativnoj kulturi vidno mesto posvećuju inovativnosti i bezrezervnoj podršci procesima generisanja novih ideja, uz uvažavanje različitih i raznovrsnih mišljenja. Imajući u vidu ubrzanje tehnoloških promena, od suštinske važnosti je da organizacije investiraju u razvoj ljudskih resursa na svim nivoima kako bi uspele da se nose sa promenama. Razvoj ljudskih resursa je dugoročna investicija (ne trošak), investicija koja se najbrže vraća.

- Tesno povezano sa prethodno pomenutim je orijentacija organizacije na vrednovanje i respektovanje pojedinaca i njihovih stvarnih potencijala. Preduzetnička kultura podrazumeva takvu atmosferu u kojoj su različite ideje i pristupi rešavanju nekih problema dobrodošli kao i jačanje svesti svakog pojedinca da je on/ona "bitna karika" u celoj priči i da neko uvažava njegovu/njenu kompetentnost.

- Da bi organizacija mogla da uči, ona nekada mora prvo da napravi greške, da ih prizna ali i da izvuče pouke iz njih kako ih ne bi ponovila. U tom kontekstu, prihvatanje rizika i sloboda da se permanentno izaziva „status quo“ i da se kroz rizikovanje ponekada napravi i greška, a da pri tome nema okrutnog kažnjavanja za eventualne propuste u poslovanju je znaćajna vrednost preduzetničke kulture.

- Samostalnost u donošenju poslovnih odluka podrazumeva odgovornost za donošenje odluka i na nižim nivoima, decentralizovane procedure odlučivanja, slobodu delovanja, delegiranje autoriteta kao i brzo i fleksibilno donošenje odluka uz minimiziranje birokratskih procedura odlučivanja.

- Ravnopravni tretman zaposlenih, bez obzira na poziciju u hijerarhiji, znači da zaposlene treba videti više kao partnere, a ne kao subordinirane zaposlene. Sistemska perspektiva u ovom kontekstu znači da svako u organizaciji bez obzira na poziciju, svojim konstruktivnim pristupom može da doprinese konkretnim rešenjima eventualnih problema sa aspekta organizacije kao celine.

- Otvorena komunikacija i kvalitetan timski rad podrazumevaju da se informacije moraju deliti. Bez otvorene komunikacije nema pouzdanih inputa u rešavanju postojećih problema. Otvorenost prema okruženju i uticajima okruženja je od posebnog značaja jer doprinosi stvaranju organizacije koja kroz interakciju sa ostalim poslovnim subjektima mnogo brže rešava svoja suštinska razvojna pitanja.

- Organizacije sa preduzetničkom kulturom visoko vrednuju akcionu orijentisanost zaposlenih i njihovu spremnost, ali i sposobnost, da poslovnu ideju koja je određeno vreme razvijana i pripremana dovedu do realizacije.

- Posvećenost poslu kao i osećaj pripadnosti određenoj organizaciji su možda ključne odrednice organizacione kulture koja ima ambicije da bude definisana kao preduzetnička. Svest o tome da kroz realizaciju ciljeva organizacije zaposleni mogu da realizuju svoje sopstvene ciljeve jača posvećenost i njihovu spremnost da se u njemu angažuju kao da su u svom sopstvenom poslu.

Da bi se pomenute vrednosti uspostavile i ugradile u korporativnom okruženju, potrebno je razviti i odgovarajuće sisteme motivacionih faktora, kako materijalnih tako i nematerijalnih. Materijalni motivatori su bitan element sistema podrške i u organizacijama predstavljaju polaznu komponentu. Međutim, ono što treba shvatiti jeste da postoje brojni nematerilani faktori koji mogu na zaposlene da utiču veoma podsticajno: interesantan posao, mogućnost napredovanja i daljeg stručnog usavršavanja, veća prava i odgovornosti, novi izazovi, korektan odnos poslodavaca, prijatna radna atmosfera, fleksibilno radno vreme, mogućnost obavljanja posla kod kuće bez potrebe da se vreme provodi u sedištu organizacije. Od suštinskog značaja je postojanje spremnosti top menadžmenta da omogući samostalnost zaposlenima i da suštinski, a ne samo deklarativno, podstiče njihovu kreativnosti i proces njihovog razvoja. Na ovaj način zaposlenima se šalje direktan signal da je organizaciji stalo do njihovog mišljenja i stava o nekom pitanju Kao veoma efikasan motivacioni faktor se pojavljuje i poverenje u zaposlene i spremnost top menadžera da svojim saradnicima dopuste da u praksi određenu ideju dovodu do tržišne realizacije.

Nagrada za izuzetnu posvećenost i lojalnost saradnika na svim nivoima odlučivanja kroz veću platu, bonuse pa čak i učešće u raspodeli profita, je trenutno najzastupljeniji oblik motivacije i nagrađivanja. Međutim, u novije vreme sve je više prisutna spremnost top menadžmenta 
da u realizaciji konkretnih projekata od interesa za organizaciju ulazi u vlasničke i partnerske odnose sa ključnim saradnicima, što kod njih stvara dodatni osećaj pripadnosti i posvećenosti organizaciji [7].

Međutim, postoje i faktori koji demotivišu korporativno preduzetništvo. Mnoge organizacije pričaju o preduzetništvu, traže od zaposlenih da se ponašaju preduzetnički, da preuzimaju rizik. Kada oni u svojim poduhvatima naprave uspeh najčešće dobiju veoma malo, a kada u svojim poduhvatima naprave neuspeh, bivaju kažnjeni (otpušteni). Drugim rečima, postoji neadekvatno ili nikakvo nagrađivanje za uspeh i surovo kažnjavanje za greške.

Pitanje koje se neminovno postavlja u uslovima turbulentnih promena poslovnog okruženja je vezano za mogući uticaj savremenih informaciono-komunikacionih tehnologija i interneta na funkcionisanje organizacije ali i prilagođavanje (promene) korporativne kulture. Organizacione promene nisu samo promene organizacione strukture, već možda i više promene organizacione kulture [8]. Ono što sigurno možemo da očekujemo, kada je u pitanju razvoj novih proizvoda i usluga, jesu konstantne i značajne promene. Jedna od najvećih promena sa kojom se suočavaju menadžeri u velikim organizacijama, a koja je već sada vidljiva, odnosi se na sve značajnije mogućnosti fleksibilnog rada i njegovog angažovanja. Kao rezultat razvoja savremenih informaciono- komunikacionih tehnologija, posebno interneta i društvenih mreža, bitno se menja radni ambijent i okruženje za obavljanje poslova. Ljudi sve više mogu svoje poslove da obave u bilo kom vremenu, na bilo kom mestu i u bilo kom formatu. Radeći kod kuće ili u nekoj virtuelnoj kancelariji, organizacija smanjuje svoje operativne troškove, povećava profitabilnost, ali istovremeno pred sebe postavlja neke izazove. Fleksibilnost rada u prvi plan postavlja potrebu za fleksibilnijim organizacionim modelima. Kako izaći na kraj sa kretanjima koja su postala potpuno nepredvidiva? Potrebne su fleksibilnije kratkoročne forme i "ad hoc" organizacije koje će se svakodnevno graditi i razgrađivati. U tom kontekstu, interesantan je model virtuelne organizacije kao privremene mreže nezavisnih subjekata koji su povezani odgovarajućim informacionim i komunikacionim sistemima. Na ovaj način organizacije dele znanja (jezgro kompetentnosti se odnosi na ono što organizacija radi posebno dobro), troškove i pristup pojedinim tržištima. Ovakve organizacije nemaju svoju centralu-direkciju, nekada ni organizacioni dijagram, mađutim savremene tehnologije im pomažu u povezivanju geografski dislociranih subjekata. Partnerstva koja nisu trajna podrazumevaju da svaki od partnera unosi svoje najače oružje tj. ono u čemu je savršen.

Njihova organizaciona kultura je po definiciji bazirana na bezrezervnoj podršci inovacijama i kontinuiranom razvoju ljudskih resursa jer samo tako mogu da održavaju svoje jezgro kompetentnosti. Međutim, ono što će biti veliki izazov za mnoge odnosi se na činjenicu da će u modelima koji su bazirani na virtuelnim organizacijama biti potrebno izgrađivati partnerske i kooperantske odnose, $\mathrm{u}$ nekim situacijama, čak i sa dojučerašnjim konkurentima. U tom kontekstu, posebno je bitno razvijati organizacionu kulturu poverenja i osećaja zajedničke posvećenosti i povezanosti u poslu.

\section{LITERATURA}

[1] E.G Flamholtz, Growing Pains - How to Make Transition from an Entrepreneurship to a Professionally Managed Firm, Jossey - Bass Publishers; San Francisco, Oxford, 1990. str. 336 - 340 .

[2] N. Janićijević, Organizaciono ponašanje, Datastatus, Beograd, 2008, str. 302-304

[3] S.P.Robbins, T.A.Judge, T.T Campbell, Organisational Behaviour, Pearson, Essex, 2010, str. 464-473

[4] M. McCrimmon, Unleash the Entrepreneur Within - how to make everyone an entrepreneur and stay efficient; Pitman Publishing, London, 1995, str.155.

[5] M. Lockhead, "In My Opinion", Management Today, September 2008, str.12

[6] M.J..Barry, E.F.Hazel, Marketing Management, MacMillan Publishing Company, New York, Oxford, Singapore, Sydney, 1993, str.596.

[7] S.Paunović, Preduzetništvo-od biznis ideje do realizacije, Fakultet za menadžment, Beograd, 2003, str.285-293.

[8] L.J. Mullins, Management and Organisational Behaviour, 9th edition, Prentice Hall, Essex, 2010, str.747.

\section{HUMAN RESOURCES AND ENTREPRENEURSHIP CULTURE IN MODERN CORPORATION \\ Abstract:}

Corporations are, like never before, under the huge pleasure to constantly struggle for their competitive position in the market. There is no long -lasting competitive advantage, what has been done yesterday should be improved today in order to survive in a turbulent environment. It is not enough just to listen to the market needs and adapt to them, it is necessary to define a business strategy which is based on the recognition of new opportunities and creating new market needs through the development of different forms of innovation. The reactive approach is increasingly giving way to a proactive, which means the full implementation of corporate entrepreneurship. It is of critical importance to design the model of organizational culture that incorporates the elements of corporate entrepreneurship. The key values of entrepreneurship culture as well as motivating factors for their effective implementation were elaborated. The development of modern information and communication technologies contributes to creation of more flexible form of organization with organizational culture that support innovations and continuous development of human resources but also mutual trust and shared commitment.

\section{Key words:}

Corporate entrepreneurship, corporate culture, entrepreneurship culture. 